\title{
Select Healthcare Transformation Library
}

Ronald S. Weinstein, MD, FCAP, FATA* and Michael J. Holcomb, BS

\begin{abstract}
The Select Healthcare Transformation Library is drawn from the Associate Editor of Book Reviews' 5000-book personal home collection and is divided into eight categories: (1) Human Intelligence and Behavior; (2) Industry Revolutions; (3) Innovation; (4) Healthcare System Transformations; (5) Education; (6) Transformational Technologies; (7) Digital Medicine; and (8) Healthcare Intervention Implementations. The select library contains 36 books that are conceptually relevant to healthcare transformation and is intended as a starting point for a reader's journey into the field of healthcare transformation.
\end{abstract}

\section{Introduction}

Healthcare transformation as a field consists of an incredibly rich continuum of opportunities to advance healthcare research, discovery, implementation, and clinical practice to improve virtually every aspect of the healthcare system. From groundbreaking science that unlocks new healthcare pathways to extending the reach of proven interventions on national and international scales, healthcare innovations have a long history of transforming healthcare, and the pace of innovation is quickening. With this in mind, we invite readers to start, or continue, their journeys in the field of healthcare transformation with a visit to our Select Healthcare Transformation Library.

To prime the pump for the immediate deployment of the book review process for the Healthcare Transformation Journal, our associate editor of Book Reviews, Dr. Ronald S. Weinstein (R.S.W.), selected 36 books from which we will draw the initial books for review. These books were borrowed from the bookshelves in R.S.W.'s 5000-book personal home library.

The Select Healthcare Transformation Library is divided into eight categories: (1) Human Intelligence and Behavior, (2) Industry Revolutions, (3) Innovation, (4) Healthcare System Transformations, (5) Education, (6) Transformational Technologies, (7) Digital Medicine, and (8) Healthcare Intervention Implementations. These categories are starting points, not limitations. New students of innovation may well be advised to start their journey into the healthcare transformation literature by giving some thought to the general topic of human creativity, the structure of scientific revolutions, and the evolutions of earlier industrial revolutions. The initial consideration of modern concepts regarding human intelligence, behavior, and creativity will set the stage for some of Healthcare Transformation Journal's anticipated running conversations on the global topic of human factors in healthcare transformations.

For each of the following eight categories of books, which we have identified as being conceptually relevant to the general topic of healthcare transformation, two to seven books are listed that provide background information for a deep dive into the core of the healthcare transformation literature and related topics. We anticipate that our readers will gain a strong foundation for healthcare transformation research and its implementations, as well as an appreciation of the many challenges that confront healthcare transformation leaders, researchers, and clinicians working in the trenches. Hopefully, we can help fuel advances in the field of healthcare innovation and transformation in an upward trajectory moving forward.

\section{Human Intelligence, Behavior, and Creativity}

- Csikszentmihalyi M. "Creativity. Flow and the Psychology of Discovery and Invention." HarperCollins Publishers, Inc., 1996, 456 pages.

- Kahneman D. "Thinking Fast and Slow." Farrar, Straus and Giroux, New York, NY, 2011, 499 pages.

Department of Telemedicine, The University of Arizona, Tucson, Arizona.

*Address correspondence to: Ronald S. Weinstein, MD, FCAP, FATA, Department of Telemedicine, The University of Arizona, 1501 N Campbell Avenue, AHSL 1156, Tucson, AZ 85724, E-mail: rweinstein@telemedicine.arizona.edu

(c) Ronald S. Weinstein and Michael J. Holcomb 2020; Published by Mary Ann Liebert, Inc. This Open Access article is distributed under the terms of the Creative Commons License (http://creativecommons.org/licenses/by/4.0), which permits unrestricted use, distribution, and reproduction in any medium, provided the original work is properly cited. 
- Sapolsky RM. "Behave. The Biology of Humans at Our Best and Worst." Penguin Press, New York, NY, 2017, 790 pages.

- Brandt A, Eagleman D. "The Runaway Species. How Human Creativity Remakes the World." Catapult, New York, NY, 2017, 296 pages.

Human intelligence, behavior, and creativity set the stage for the world's great societal transformations. Much of what happens in a revolution or a transformation process is driven by human behavior. The outstanding book by M. Csikszentmihalyi is somewhat dated, but reading it is a reminder that the past matters when we think about creativity and the execution of transformative human activities. D. Kahneman's “Thinking Fast and Slow" is a must read for students of the human mind, written by one of the most influential psychologists in the world. R.M. Sapolsky's "Behave" is a landmark publication that probed the range of human behavior, from the good to the bad and the ugly. Societal healthcare transformations must deal with remarkably diverse human populations as the healthcare service users. A. Brandt and D. Eagleman's “The Runaway Species" identifies many facets of human creativity in their popular book.

\section{Societal Revolutions}

- Kuhn TS. "The Structure of Scientific Revolutions," Third Edition. University of Chicago Press, Chicago, IL, 1996, 212 pages.

- Morris CR. "The Dawn of Innovation. The First American Industrial Revolution." Public Affairs, New York, NY, 2012, 368 pages.

- Schwab K. "The Fourth Industrial Revolution." Crown Business, New York, NY, 2017

Thomas S. Kuhn (1922-1996) was a professor emeritus of linguistics and philosophy at the Massachusetts Institute of Technology. Kuhn's third edition of his classic publication "The Structure of Scientific Revolutions," published in 1996 just before his death, and three decades after the publication of its first edition, is a book that has had an influence far beyond its original intended audience. It provides the best explanation of the processes of discovery to date.

C.R. Morris" "Dawn of Innovation" is one of the best descriptions of the first American Industrial Revolution, the first of four. It is interesting to trace the history of an entire American Industrial Revolution, and to learn how these things work out. Morris' history details, at a granular level, the myriad of inventions, innovations, and system microtransformations that propelled the first industrial revolution forward.
Celebrations of Klaus Schwab's "Fourth Industrial Revolution" are currently the rage among healthcare leaders who see the confluence of digital technologies, robotics, and artificial intelligence (AI) at every crossroads on our march to that aspirational 22nd century "disease-free world."

\section{Innovation}

- Rogers EM. "Diffusion of Innovations," 5th edition. Free Press, New York, NY, 2003.

- Christensen CM, Anthony SD, Roth EA. "Seeing What's Next. Using the Theories of Innovation to Predict Industry Change." Harvard Business School Press, Boston, MA, 2004, 312 pages.

- Christensen CM, Grossman JH, Hwang J. "The Innovator's Prescription. A Disruptive Solution for Health Care." McGraw Hill, New York, 2008, 496 pages.

- Dyer J, Gregersen H, Christensen C. "The Innovators DNA. Mastering the Five Skills of Disruptive Innovators." Harvard Business Review Press, Cambridge, MA, 2011, 272 pages.

- Christensen CM, Grossman JH, Hwang J. "The Innovator's Dilemma. When New Technologies Cause Great Firms to Fail." Harvard Business Review Press, Cambridge, MA, 2013, 256 pages.*

- Ridley M. "The Evolution of Everything. How New Ideas Emerge." HarperCollins, New York, NY, 2015, 360 pages.

- Poole S. "Rethink. The Surprising History of New Ideas." Scribner, New York, NY, 2016, 342 pages.

E.M. Rogers' "Diffusion of Innovations," is in its 5th edition. It describes what are now regarded as the classic stages in the development and diffusion of innovations. Rogers' concepts have been integral to what is now considered to be common knowledge about how the innovation processes work.

Clayton M. Christensen, PhD, was a Harvard Business School distinguished professor, was a major figure in the world of innovation science. His “The Innovator's Prescription" produced a wellspring of ideas that proved foundational to our understanding of how many successful products and services evolve. The book has provided a road map for reinventing transformation of healthcare delivery systems in the United States in the future. His other books expand on his theory of disruptive innovation.

M. Ridley's "The Evolution of Everything" and S. Poole's "Rethink" are interesting reads that highlight 
the broad range of sources of new ideas, including the recycling of older ideas, that pop up as newer innovations within a later time frame.

\section{Healthcare System Transformations}

- Blumenthal D, Morone JA. "The Heart of Power. Health and Politics in the Oval Office." University of California Press, Berkeley, CA, 2009, 484 pages.

- Emanuel EJ. "Reinventing American Health Care. How the Affordable Care Act Will Improve our Terribly Complex, Blatantly Unjust, Outrageously Expensive, Grossly Inefficient, Error Prone System." Public Affairs, New York, NY, 2014, 380 pages.

- Phillips RA. “America's Healthcare Transformation. Strategies and Innovations." Rutgers University Press, 2016, 376 pages.

- Haseltine WA. "World Class. A Story of Adversity, Transformation, and Success at NYULangone Health." Fast company Press, New York, NY, 2019, 340 pages.

D. Blumenthal and J.A. Morone's "The Heart of Power" is a presidential history that takes the reader through the evolution of healthcare policy during 11 U.S. presidencies, starting with Franklin D. Roosevelt and continuing on through George W. Bush's presidency. It shows the centricity of the U.S. president in the decision-making that affects the healthcare of large swaths of the U.S. population.

E.J. Emanuel's "Reinventing American Health Care" is essential reading for anyone interested in understanding how the U.S. healthcare system functions and for anyone who wishes to tackle transforming our byzantine U.S. healthcare system into something new that functions well and fairly for all Americans. Emanuel's "Reinventing American Health Care" presents a detailed case study of how brilliantly conceived healthcare policy, and its enabling legislation, can actually accomplish healthcare transformation within a highly fragmented healthcare delivery system. It gives reason for hope for successful future healthcare system transformation.

R.A. Phillips "America's Healthcare Transformation" is a collection of articles that give testimony to the remarkable complexity of today's healthcare systems.

W.A. Hazeltine's book, entitled "World Class," is an inspiring accounting of the recent "bailout" and socalled transformation of a large university healthcare system in New York City. This remarkable academic healthcare system rehabilitation story deserves special mention, in the hopes that it will inspire other philanthropists to make comparable investments in our future.

The rehabilitation process at New York UniversityLangone was led by a visionary, arguably a one-of-a kind, New York City billionaire who achieved total personal emersion in his mission to make New York UniversityLangone the "best-of-breed" healthcare system in the New York City area. He succeeded according to a number of measures of excellence. A hurricane's destruction was defeated. National Institutes of Health research funding skyrocketed. Patient services improved dramatically. Exceptionally talented physician-scientists and $\mathrm{PhD}$-scientists flocked to NYU-Langone. Medical students at NYULangone were given tuition-free medical education.

W.A. Hazeltine, an accomplished Harvard professorscientist-entrepreneur, proved to be a "world class" story teller as well. Although the turn around of NYULangone is a notable accomplishment, even a local "transformation" by some standards, it does not rise to the level of being a societal transformation for healthcare in America. In fact, it has had little impact beyond New York City, aside from the matching of the "tuition-free" benefit for medical students at Johns Hopkins University School of Medicine. Let us clone the billionaire Michael Bloomberg, the former mayor of New York City, who is the donor behind Johns Hopkins "tuition-free" medical education benefit for their students.

\section{Education}

- Cook-Sather A. "Education is Translation. A Metaphor for Change in Learning and Teaching." University of Pennsylvania Press, Philadelphia, PA, 2006, 208 pages.

- Christensen CM, "Disrupting Class. How Disruptive Innovation Will Change the Way the World Learns." McGraw Hill, New York, NY, 2008, 238 pages.

- Bowen WG, Chingos MM, McPherson MS. "Crossing the Finish Line. Completing College at America's Public Universities." Princeton University Press, Princeton, NJ, 2009, 389 pages.

- Turkle S. "Reclaiming Conversation. The Power of Talk in a Digital Age." Penguin Press, New York, NY, 2015, 436 pages.

- Fisher JF, Fisher D. "Who You Know. Unlocking Innovations that Expand Students' Networks." Jossey-Bass, San Francisco, CA, 2018, 180 pages.

Education and training, across the entire U.S. education continuum, is a significant challenge for planners of next-generation healthcare systems. Although its widely acknowledged that patients, and their care givers, will be 
expected to assume greater roles in their own healthcare in the future, millions of individuals lack basic health literacy. Levels of basic population health literacy in the United States are among the lowest for countries in the industrialized world. Low levels of health literacy will impede efforts to disseminate and implement findings from implementation science and implementation research down the road.

In the United States, our education system is, arguably, as fragmented as, and even more dysfunctional than, the byzantine U.S. healthcare delivery system. And, the U.S. education system is even more resistant to change. We are faced with a reality that upgrading the U.S. education system to a level say, that of Finland, might be less expensive but more politically charged than transforming healthcare today. Yet, elevating the level of health literacy in the general population, through education reform, may be essential to making tomorrow's evolving healthcare systems actually work.

A. Cook-Sather writes about how to engage students in their learning.

W.G. Bowen et al.'s, "Crossing the Finish Line"' is a sobering discussion of the challenges facing state universities in the United States. The ambivalence of state legislatures in funding their state universities is a significant societal problem.

S. Turkle's "Reclaiming Conversation" is an interesting read. Social media is reinventing how people communicate with one another. The advent of social media is likely to be an enabler of next-generation healthcare transformations.

Finally, this interesting book, "Who You Know...," coauthored by J.F. Fisher and D. Fisher, highlights the importance of engagement and networking in many human activities. Soft skills, such as networking skills, are becoming targets of interest and concern among educators. Are networking skills sacrificed in distance learning activities? Should training in soft skills be added to the curriculums of health professions schools? Is it important to learn how to network with influential people? At what grade level in the education continuum should attention be directed to networking skills?

Transformational Technologies: (Computers, Al, Automation, Robotics, etc.)

- Evans H. "They Made America. From the Steam Engine to the Search Engine. Two Centuries of Innovators." Little Brown and Company, New York, NY, 2004, 496 pages.

- Ford M. "Rise of the Robots. Technology and the Threat of a Jobless Future." Basic Books, New York, 2015, 334 pages.
- Mindell D.A. “Our Robots, Ourselves. Robotics and the Myths of Autonomy." Viking, New York, NY, 2015, 360 pages.

- Barrat J. "Our Final Inventions. Artificial Intelligence and the End of the Human Era." Thomas Dunne Books, New York, NY, 2013, 322 pages.

- Topol E. "Deep Medicine. How Artificial Intelligence Can Make Healthcare Human Again." Basic Books, New York, NY, 2019, 378 pages.

- Winchester S. “The Perfectionists. How Precision Engineers Created the Modern World." Harper Perennial, New York, NY, 2018, 395 pages.*

Evans' highly readable anthology shows how new technologies are often behind the creation of new industrial revolutions and their accompanying social transformations. We are currently witnessing astonishing advances in computer science, robotics, AI, and automation, as major drivers of transformation in society across many business sectors. The book authored by M. Ford entitled "Rise of Robots" provides a vision of what impact robots could have on the job market. D.A. Mindell's “Our Robots, Ourselves, Robotics, and the Myths of Autonomy" questions the impact of robots on society in the future. J. Barrat's "Our Final Inventions," and E. Topol's "Deep Medicine”, published 6 years later provide authoritative discussions of healthcare systems being deeply influenced by the intrusion of AI and deep learning as potential over-arching influences in a future healthcare delivery world. Finally, Simon Winchester reminds us, in his intellectual romp, "The Perfectionists," that at the end of the day, it is the engineers who may matter most when it comes to societal transformations.

Eric Topol, MD., the author of the best-selling book, "Deep Medicine. How Artificial Intelligence Can Make Healthcare Human Again," is emerging as the face of medical AI and deep learning. His book, "Deep Medicine" is a masterpiece of scientific reporting. It reflects 3 years of intensive study and authoring by a highly regarded physician scholar. Dr. Topol is a brilliant academic cardiologist with extraordinary analytical and writing skills. He is a genuine student of both medical innovation and medical practice. Dr. Topol is that rare physician-practitioner who is exceptionally bright, possesses the legendary Dr. Fuller Albright's "three-story imagination with a sky-light," and displays boundless intellectual curiosity, energy, and optimism. What is particularly impressive is that Dr. Topol has one foot firmly embedded in his practice of clinical medicine, to which he has been devoted for decades, and the other foot firmly planted in AI and deep learning start-up industries. Although it seems that nobody could be prouder to be a 
card-carrying physician than Dr. Topol, Dr. Topol also tracks the progress of scores of start-up companies, works with an impressive list of leaders of major corporations, and sits on prestigious corporate Boards-ofDirectors and advisory committees.

Dr. Topol is this book reviewer's candidate for the title, "Modern-Day Sir William Osler." R.S.W. has had a career-long interest in the life and career of the original Sir William Osler, and have personally run summer Sir William Osler Summer Fellowship programs for high school and college students, since 1978. As was the case for Sir William Osler a century ago, Dr. Topol is similarly committed to remain involved in hands-on patient care, seemingly the joy of his professional life. Sir William Osler was a communicator par excellence with an international following. "Deep Medicine" is Dr. Topol's third book on medical innovation and its potential influences on the transformation of healthcare.

"Deep Medicine" provides an engrossing description of what amounts to a "virtual" multiyear tour of the AI and deep learning industries by one of the leading academic physicians of our times. The final chapter, entitled "Deep Empathy,"' is heart-felt and highly personal. It is inspirational to have a professional engaged in computerbased medicine with Dr. Topol's level of loyalty to his roots as a traditional hands-on physician. This final chapter, which we recommend that medical students read first, is Dr. Eric Topol's manifesto envisioning how the future of medical care could unfold in a technology-enabled world. Dr. Topol describes what medical practice could look like when the thousands of computer-enabled individual components of the healthcare delivery system become interconnected into a single interconnected digital landscape, a truly transformative future for the medical practice environment, one in which doctors are freed up from their back office menial tasks (scheduling appointments, billing for services, electronic health record chart reviews, etc.) allowing them to return to pure "caring" for patients, hands-on, in a highly personal patient-centric way. According to this scenario, the medical science field, and medical humanities field, would link up together and begin to fuse. We hope this comes true.

\section{Digital Medicine}

- Topol E. "The Creative Destruction of Medicine. How the Digital Revolution Will Create Better Health Care." Basic Books, 2011, 320 pages.*

- Topol E. "The Patient Will See You Now. The Future of Medicine is in Your Hands." Basic Books, New York, 2015, 374 pages.
- Wachter R. "The Digital Doctor. Hope, Hype, and Harm at the Dawn of Medicine's Computer Age." McGraw Hill, New York, NY, 2015, 330 pages.

- André A. "Digital Medicine." Springer International Publishing, 2018, 115 pages.

- Clapshaw C. "The Future of Healthcare is Digital.” HISA, 2018, 66 pages.

What is the picture of healthcare once the current wave of innovations in digital technologies is in full blossom? What might the healthcare system look like? Where are we if, and when, the traditional doctor-patient relationship that has provided the backbone for healthcare systems, as we knew them for past centuries, is a thing of the past? Topol has published a series of books that include discussions of such "what if" conversations. Wachter's "The Digital Doctor" discusses the possibilities for progress in a digital age from the perspective of a medical practice leader deeply embedded as a practicing physician in San Francisco. André's "Digital Medicine" and Clapshaw's "The Future of Healthcare is Digital" give brief regional updates on digital medicine in Australia and France, respectively. There is so much more to come.

\section{Healthcare Intervention Implementations}

- Brownson RC. Colditz GA, Proctor EK. "Dissemination and Implementation Research in Health. Translating Science to Practice." Oxford University Press, New York, NY, 2018, 515 pages.

- Chambers DA, Vinson CA, Norton WE, eds. "Advancing the Science of Implementation Across the Cancer Continuum." Oxford University Press., New York, NY, 2019, 409 pages.

R.C. Brownson et al.'s "Dissemination and Implementation Research in Health" and D.A. Chambers et al.'s. "Advancing the Science of Implementation Across the Cancer Continuum" are two recently published books on dissemination and implementation research, both published by Oxford University Press. Both books rapidly became "required reading" in the "clinical dissemination and implementation of research in healthcare" field. These books are essential reading for clinical investigators interested in carrying out U.S. federally funded intervention studies. They are also suitable for use as classroom text books on "how to do it." Dissemination and implementation research funding represents a miniscule part of the annual U.S. biomedical research budget. This is tragic, given the wealth of quality clinical research outcomes that never see the light of day in everyday clinical practice. 
R.C. Brownson et al.'s "Dissemination and Implementation Research in Health" is inclusive and covers a broad spectrum of topics ranging from introductory terminology and the historical roots of dissemination and implementation research to dissemination and implementation research in a global context. There are 29 multiauthor chapters, which are remarkably uniform with respect to readability and the anticipated level of education of the target audience. Discussions of complex issues are presented in easy to understand language. This is noteworthy in light of the interdisciplinary nature of the intended audiences. Interestingly, the development of newer theoretical frameworks for implementation research has accelerated in recent years. The text is remarkably up to date.

D.A. Chambers et al.'s "Advancing the Science of Implementation Across the Cancer Continuum" can be viewed as an extension of Brownson et al.'s, "Dissemination and Implementation Research in Health." In addition to reiterating, and expanding on, introductory material in Brownson et al.'s "Dissemination and Imple- mentation Research in Health," and also expanding on certain other topics, such as the history of NIH funding for Dissemination and Implementation Research (see page 18), the Chambers book focuses on a single disease entity, cancer, and includes a series of chapters describing 19 highly informative case studies. These case studies will be of general interest and may prove to be of special value for non-MD investigators who do not have direct patient care as part of their job descriptions.

We hope that publication of this important pair of Oxford University Press books, by top authorities in the dissemination and implementation research fields, will help catalyze an expansion of funding for dissemination and implementation research in the near future. Leaders in academic medicine would do well to read these books and jump on board as advocates for this often undervalued, but essential, component of healthcare transformation processes. No doubt about it, "the devil is in the details" when it comes to making a difference in large scale transformative processes! 